\title{
Comparison of Shear Bond Strength of Packable Glass Ionomer Cement, Resin Modified Glass Ionomer Cement, Compomer and Giomer to Primary and Permanent Teeth - An In Vitro Study
}

\author{
Pooja Singh¹, Manish Jha², Kashika Arora ${ }^{3}$, Deepa Bhat ${ }^{4}$, Kiran Awchat ${ }^{5}$, Garima Goyal6, Malay Mitra7
}

\begin{abstract}
${ }^{1}$ Department of Pedodontics and Preventive Dentistry, KSD Jain Dental College \& Hospital, Kolkata, West Bengal, India. ${ }^{2}$ Department of Orthodontics and Dentofacial Orthopaedics, Guru Nanak Institute of Dental Sciences \& Research, Kolkata, West Bengal, India. ${ }^{3}$ Department of Pedodontics and Preventive Dentistry, Mumbai, India. ${ }^{4}$ Department of Pedodontics and Preventive Dentistry, Awadh Dental College and Hospital, Jamshedpur, Jharkhand, India. ${ }^{5}$ Department of Prosthodontics, Armed Forces Dental Clinic, New Delhi, India. ${ }^{6}$ Department of Orthodontics and Dentofacial Orthopaedics, Mahatma Gandhi Dental College and Hospital, Jaipur, Rajasthan, India. ${ }^{7}$ Department of Pedodontics and Preventive Dentistry, Dr. R. Ahmed Dental College \& Hospital, Kolkata, West Bengal, India.
\end{abstract}

\section{ABSTRACT}

\section{BACKGROUND}

With the changing demand in dentistry, a wide range of dental materials is present in the market today. Choosing the best material for a given situation becomes confusing for a clinician. Shear bond strength gives an idea of retentiveness of a material partially. The purpose of the study was to determine and compare shear bond strength (SBS) of packable glass ionomer cement (GIC), resin- modified glass ionomer cement (RMGIC), compomer, and giomer to primary and permanent teeth.

\section{METHODS}

An in-vitro, experimental study was done. 60 freshly extracted permanent first premolars, extracted for orthodontic purpose and 60 freshly extracted over-retained deciduous molars were collected and kept in two groups. Specimens in each group were randomly divided into six subgroups depending on the material to be used. Flat dentinal surface on tooth was prepared over which restorative materials were placed. The prepared specimen was subjected to shear test and the value obtained was compared. Descriptive statistical analysis was performed to calculate the mean shear bond strength of each group. Also, analysis of variance (ANOVA) followed by Tukey's test was performed with the help of critical difference (CD) at $5 \%$ and $1 \%$ level of significance. The debonded specimen were examined to assess the mode of failure.

\section{RESULTS}

Intragroup comparison for primary teeth showed that composite resin had the highest shear bond strength value (16.21 \pm 1.12$)$, followed by Giomer (14.25 \pm 1.13$)$, compomer $(10.27 \pm 1.38)$, RMGIC $(6.06 \pm 1.04)$, packable GIC $(3.01 \pm 0.85)$ and conventional GIC $(2.94$ \pm 0.91 ). In permanent teeth, similar order was seen with composite resin showing highest bond strength $(17.82 \pm 1.50)$ followed by Giomer (15.26 \pm 1.54$)$, compomer $(12.54 \pm 1.36)$, RMGIC (7.00 \pm 0.89$)$, packable GIC $(3.35 \pm 0.98)$ and conventional GIC $(3.30 \pm 1.03)$. Intergroup comparison revealed, the values of shear bond strength (SBS) of all the materials tested was lower in primary teeth. However, the difference was statistically insignificant for conventional GIC and packable GIC. The mode of failure for packable GIC specimens was cohesive within the material, which suggests that the values obtained may not be the strength of the bonded interface but the strength of the material. In RMGIC it was predominantly mixed (cohesive within the material), which indicates that the values obtained were not clearly the strength of the bonded interface but due to inherent weakness of the material. The mode of failure in compomer and Giomer was adhesive failure suggesting that the value obtained was of adhesive bond formed at the interface.

\section{CONCLUSIONS}

Giomer and compomer proved to be the materials with high adhesiveness, so these can be recommended as a suitable restorative material for both primary and permanent teeth. Of the four materials tested, Giomer was found to be the best in terms of SBS in both the primary and permanent teeth.

\section{KEY WORDS}

Compomer, Glomer, Packable GIC, RMGIC, Shear Bond Strength
Corresponding Author:

Dr. Pooja Singh,

Flat No. A/4, EE-145, Near Tank no. 10, Salt Lake, Kolkata, West Bengal, India.

E-mail: poojapedo808@gmail.com

DOI: $10.14260 / \mathrm{jemds} / 2021 / 301$

How to Cite This Article:

Singh P, Jha M, Arora K, et al. Comparison of shear bond strength of packable glass ionomer cement, resin modified glass ionomer cement, compomer and giomer to primary and permanent teeth - an in vitro study. I Evolution Med Dent Sci 2021;10(19):1429-1434, 10.14260/jemds/2021/301

Submission 14-12-2020,

Peer Review 24-02-2021,

Acceptance 02-03-2021,

Published 10-05-2021.

Copyright (c) 2021 Pooja Singh et al. This is an open access article distributed under Creative Commons Attribution License [Attribution 4.0 International (CC BY 4.0)] 


\section{BACKGROUND}

Healthcare professionals have always been plagued by the problem of restoring parts of body lost as a result of accident or disease. Dental practitioners have also been confronted with this problem since the beginning of dental practice, and the means of replacing missing tooth structure by artificial materials continues to account for a larger part of dental science. ${ }^{1}$ Dental amalgam has been the restorative material of choice for many decades. However, in recent years, there has been an increasing concern about the safety of dental amalgam, mainly in respect to possible mercury toxicity. ${ }^{2}$ Also the increasing demand for aesthetics have directed the dental professionals to develop alternative restorative materials. In the current age of adhesive dentistry conservation of tooth structure is of paramount importance. ${ }^{3}$ The use of bonded restorations in children has a significant importance considering the small size of deciduous teeth.

From 1950's to the mid 1980's, two categories of direct tooth-coloured adhesive restorative materials were available to the dentists: Composite resins and glass ionomer cement. Glass ionomer cements (GIC) were first introduced to the dental profession by Wilson and Kent in $1972 .{ }^{4}$ The main characteristic of GIC is the ability to chemically bond to enamel and dentin. Recently, several faster setting, high-viscosity glass ionomer cements have been introduced in the market commonly called as viscous, packable or condensable glass ionomer cements. As individual material categories both composite resins and glass ionomer cement restorative materials exhibit significant advantages as well as limitations. In order to exploit the advantages of each material and simultaneously minimise their shortcomings, the development of materials combining composite resin and glass ionomer cement has taken place. 5 Broadly, three categories of such materials have been developed; resin modified glass ionomer cement (RMGIC), poly acid modified composite resin (compomers) and most recently giomers which contain pre-reacted glass ionomer particles. The first resin-modified glass ionomer cements (RMGIC) were introduced in the late 1980s (Antonucci et al. 1988; Mitra, 1989). The light-cured glass ionomers were developed chiefly to overcome the problems of moisture sensitivity and low early mechanical strength. The compomers, as the name implies, combine the characteristics of both composite resin and glass ionomers into a single component. The term 'polyacid modified resin composites' appears more appropriate for this material. In 2002 Pre- Reacted Glass Ionomer-Composites (GIOMERS) which uses pre-reacted glass ionomer technology to form a stable phase of Glass Ionomer Cement in the restoration was developed. Giomer has the advantage of fluoride recharge, biocompatibility, smooth surface finish, excellent aesthetics, and clinical stability.

It is difficult for a clinician to choose the best material for a given circumstance. Longevity of a restoration depends in part on the ability of a material to adhere to tooth which can be measured by lab test. Though lab tests for bonding ability have been criticized and their validity questioned but present evidence suggest that clinical performance can be predicted by these tests. A number of tests are available for testing materials in different circumstances like Shear bond strength, tensile bond strength, push out strength etc. In this study SBS was chosen as it is an easy and widely accepted method to predict retention of an adhesive restorative material. ${ }^{6}$ Also a restored tooth tends to transfer stress differently from that of a normal tooth. Any force on the restoration produces compression, tension or shear along the tooth restoration interface, ${ }^{7}$ leading to more complex stress distribution which is a combination of compressive, tensile and shear stresses. ${ }^{8}$ Since the process of mastication is one of the indentation, basically related to shearing phenomenon, the true nature of adhesive strength of the materials at the interface is depicted by the shear bond strength. To improve the validity of dental adhesive evaluations it is suggested that existing variables that are standardized by the International Organization for Standardization should be adhered to by the researchers and products should undergo a combination of testing. So, this study was done in adherence to ISO TS no 11405 also both quantitative and qualitative evaluation of samples was done i.e. numerical value of bond strength compared and also the debonded surfaces were evaluated for the mode of failure. Though literature on SBS of adhesive material to permanent teeth is profound but results are unreliable as standard protocols were not followed and studies on primary teeth is scarce. In light of the existing knowledge and scope of further study this study was done to compare the shear bond strength of packable GIC, RMGIC, compomer, giomer to primary and permanent tooth keeping conventional GIC as negative control and composite resin as positive control followed by evaluation of nature of debonding.

\section{METHODS}

An in-vitro, experimental study was carried out in the Department of Pedodontics \& Preventive Dentistry at Dr. R. Ahmed Dental College \& Hospital, Kolkata and School of Bioscience and Engineering, Jadavpur University, Kolkata for a period of 2 years from September 2012 to September 2014.

120 freshly extracted teeth were used for the study. Sample size calculation was done by 'Resource Equation' method in which E (sample size) was measured, which is the degree of freedom of ANOVA. Value of $E$ should lie between 10 and 20. $\mathrm{E}=$ Total no of participants - total no of groups. In this study for each material $\mathrm{E}=20-2=18$. Of the total 120 teeth used 60 freshly extracted permanent first premolars, extracted for orthodontic purpose and 60 extracted overretained deciduous molars, were collected from the exodontia clinic of the Department of Pedodontics \& Preventive Dentistry after obtaining the patients' informed consent under a protocol reviewed \& approved by ethical board of $\mathrm{Dr}$ R. Ahmed Dental College and Hospital. Only caries free, sound teeth were used. Teeth with visible and detectable caries, hypoplastic stains, white spots, cracks, erosion and root canal treated teeth were excluded for avoiding error. Of the 120 teeth used 60 permanent teeth, placed in Group A and 60 primary teeth placed in group $B$. Specimen in each group $A$ and B were randomly divided into 6 Subgroups (A1 - A6) and (B1 B6) sub-group A1, B1: teeth bonded with conventional GIC (GC Gold Label 2 Universal Restorative; GC India Dental Pvt Ltd.), sub-group A2, B2: teeth bonded with packable GIC (GC Gold Label 9 High strength posterior restorative; GC India Dental Pvt Ltd.), sub-group A3, B3: teeth bonded with RMGIC (GC Gold Label LC 2 Light-Cured Universal Restorative; GC India Pvt Ltd.), sub-group A4, B4: Teeth bonded with Compomer 
(DYRACT XP; Dentsply Germany), sub-group A5, B5: Teeth bonded with Giomer (Beautifil II; Shofu Inc, Kyoto, Japan.), sub-group A6, B6: Teeth bonded with Composite Resin (Tetric N-Ceram Ivoclar Vivadent Marketing India Pvt. Ltd.).

After extraction teeth were cleaned and stored in distilled water to avoid dehydration of the specimens and used for testing within one week. Teeth were mounted on self-cure acrylic resin. Flat dentinal surfaces on tooth was prepared at the same depth of dentin by trimming. The exposed surface of the tooth was smoothened using the silicon carbide paper under running water. Grinding was done until the surface was even and smooth when inspected under $2 \mathrm{X}$ magnification.

The tooth surface was then prepared according to the manufacturer's instructions. An adhesive tape with a hole of $3 \mathrm{~mm}$ diameter was applied to the tooth surface to limit the bonded area. Plastic mould was positioned over the hole in the adhesive tape and filled with restorative materials. The mould and adhesive tape were removed after setting of the restorative material. The specimen was positioned in the loading rig of Instron $5500 \mathrm{R}$. with the adhesive interface within $0.5 \mathrm{~mm}$ of the shearing blade and subjected to shear test with crosshead speed $0.75 \mathrm{~mm} / \mathrm{min}$.

The force value obtained after debonding the samples was converted to bond strength by dividing the force value by the surface area over which the force was applied. The value thus obtained was of the shear bond strength.

\section{Statistical Analysis}

Descriptive statistical analysis was performed to calculate the mean shear bond strength of each group with corresponding standard deviations (S.D.). Also, One-way analysis of variance (ANOVA) followed by Tukey's test was performed with the help of critical difference (CD) or least significant difference (LSD) at $5 \%$ and $1 \%$ level of significance to compare the mean values for both inter and intra group comparison. $\mathrm{P} \leq 0.05$ was taken to be statistically significant. The debonded specimens were examined by Scanning electron microscope to determine the mode of failure.

\section{RESULTS}

\section{Intragroup Comparison}

\begin{tabular}{|c|c|c|c|c|c|c|}
\hline 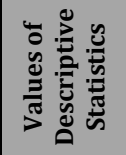 & 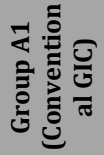 & 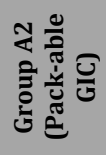 & 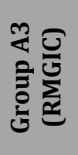 & 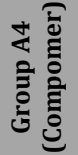 & 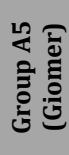 & 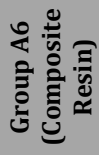 \\
\hline Mean \pm S.D. & $\begin{array}{c}3.30 \\
\pm \\
1.03\end{array}$ & $\begin{array}{c}3.35 \\
\pm \\
0.98\end{array}$ & $\begin{array}{c}7.00 \\
\pm \\
0.89\end{array}$ & $\begin{array}{c}12.54 \\
\pm \\
1.36\end{array}$ & $\begin{array}{c}15.26 \\
\pm \\
1.54\end{array}$ & $\begin{array}{c}17.82 \\
\pm \\
1.50\end{array}$ \\
\hline Median & 3.28 & 3.27 & 7.16 & 12.03 & 15.40 & 18.00 \\
\hline Range & $\begin{array}{c}1.87 \\
- \\
4.90\end{array}$ & $\begin{array}{c}1.99 \\
- \\
4.88\end{array}$ & $\begin{array}{c}5.54 \\
- \\
8.01\end{array}$ & $\begin{array}{c}11.00 \\
- \\
15.00\end{array}$ & $\begin{array}{c}12.80 \\
- \\
18.00\end{array}$ & $\begin{array}{c}15.20 \\
- \\
20.00\end{array}$ \\
\hline
\end{tabular}

Of all the restorative materials tested shear bond strength value of conventional GIC to permanent teeth is minimum and that of composite resin is maximum. The values of packable
GIC, RMGIC, Compomer and Giomer lies in between the values of conventional GIC and composite resin in increasing order.

\begin{tabular}{|cccccc|}
\hline Source & D. F. & $\begin{array}{c}\text { Sums of } \\
\text { Squares }\end{array}$ & $\begin{array}{l}\text { Mean sum } \\
\text { of Squares }\end{array}$ & 'F' & 'P' \\
Between groups & 5 & 1933.25 & 386.65 & 248.23 & $<0.01^{*}$ \\
Residual & 54 & 84.10 & 1.55 & - & \\
Total & $\mathbf{5 9}$ & $\mathbf{2 0 1 7 . 3 5}$ & - & - & \\
\hline \multicolumn{5}{|c}{ Table 2. ANOVA Table for Shear Bond Strength } \\
of Materials to Permanent Teeth & \\
\hline \multicolumn{7}{|c}{}
\end{tabular}

D.F. - Degrees of Freedom, F - F - Statistic * - Statistically Significant ANOVA showed that there was significant difference between groups for permanent teeth $\left(\mathrm{F}_{5,54}=248.23\right.$; $\mathrm{P}<0.01$ ).

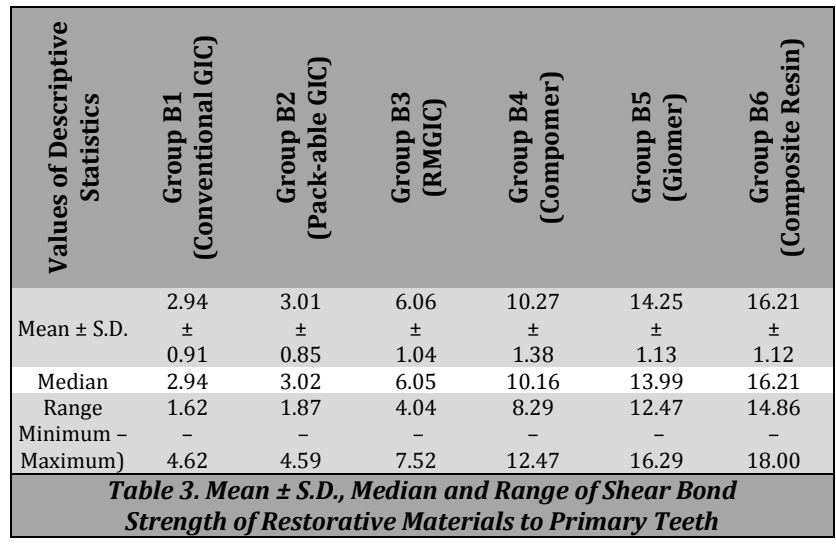

\begin{tabular}{|c|c|c|c|c|c|}
\hline Source & D.F. & $\begin{array}{l}\text { Sums of } \\
\text { Squares }\end{array}$ & $\begin{array}{l}\text { Mean Sum } \\
\text { of Squares }\end{array}$ & 'F' & 'p' \\
\hline Between groups & 5 & 1621.26 & 324.25 & 272.95 & $<0.01^{*}$ \\
\hline Residual & 54 & 64.14 & 1.18 & - & \\
\hline Total & 59 & 1685.41 & - & - & \\
\hline \multicolumn{6}{|c|}{ Table 4. ANOVA Table for SBS of Materials to Primary Teeth } \\
\hline
\end{tabular}

D.F. - Degrees of Freedom, F - F - Statistic, * - statistically significant. ANOVA showed that there was significant difference between groups for primary teeth $\left(\mathrm{F}_{5,54}=272.95 ; \mathrm{P}\right.$ $<0.01$ ).

Shear bond strength value (SBS) of Conventional GIC to primary teeth was the least and that of composite resin to primary teeth was the highest among the restorative materials tested. The bond strength values of packable GIC, RMGIC, Compomer and Giomer lies between the values of conventional GIC and composite resin in an increasing order.

Tukey's Test was performed with the help of Critical Difference (CD) or Least Significant Difference (LSD) at $5 \%$ and $1 \%$ level of significance to compare the mean values.

There was no significant difference between the mean values of Conventional GIC and packable GIC ( $p>0.05)$. However, the mean values significantly increased for RMGIC, Compomer, Giomer and Composite resin which was significantly highestfor composite resin.

\section{Intergroup Comparison}

Bond strength of each material was compared to primary and permanent teeth individually. ANOVA and Tukey test showed there was no significant difference between the values of conventional GIC and packable GIC for permanent and primary however there was significant difference between SBS values of RMGIC, Compomer, Giomer and composite for permanent 
and primary teeth. As per CD the mean value of RMGIC, Compomer, Giomer and Composite for permanent was significantly higher than that for primary.

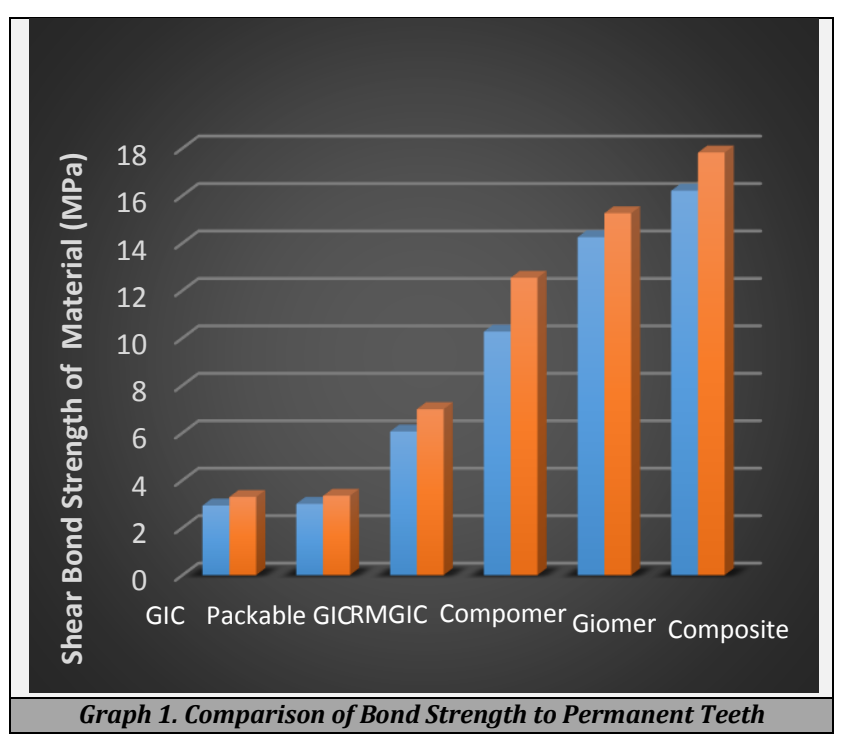

\section{DISCUSSION}

Shear bond evaluation is only one of the many in-vitro screening tests that could be done to predict the ultimate clinical success of adhesive material. However, the validity of shear bond strength studies, as predictors of clinical success is questioned because of many possible variables that influence in vitro bond strength to dentin, such as the type and age of the teeth, the degree of dentin mineralization, the dentinal surface being bonded, the storage media, the environmental relative humidity and the fact that standardization is so difficult to achieve.9-11 This study was performed according to the recommendation of the International Standards Organization (ISO) technical specification no 11405 . Only caries free teeth were used in this study. ${ }^{12}$ The teeth were stored in distilled water as recommended by Strawn et al. to avoid changes of the dentin substrate, since alterations of the substrate caused by storage solutions can affect bond strength studies and the sample testing was done within 1 week of storage after extraction. ${ }^{13}$ Bond strength has been shown to be higher in superficial than in deeper part of dentin. This study followed the suggestions by Rueggeberg and Causton ${ }^{14,15}$ to carry out bond strength testing after the tooth was sectioned $1 \mathrm{~mm}$ below the DEJ in order to control variables for comparative testing. The surface area of bonded surface was specified and stress applied to the specimen at a cross head speed of 0.75 $\mathrm{mm}$ per min as recommended by ISO. ${ }^{12}$

In the present study, shear bond strength (SBS) of Conventional GIC to primary tooth was found to be $2.94 \pm 0.91$ $\mathrm{MPa}$ and that to permanent tooth was found to be $3.30 \pm 1.03$ $\mathrm{MPa}$ and there was no significant difference between the groups. This result was in accordance to the value obtained by Somani R, Jaidka S, Singh D.J., Sibal G.K (2016). ${ }^{16}$ SBS value obtained for packable GIC to primary tooth was $3.01 \pm 0.85$ $\mathrm{MPa}$ and to permanent tooth was $3.35 \pm 0.98 \mathrm{MPa}$. There was no significant difference between the values obtained for permanent and primary tooth which was in accordance with the study performed by Raju V.G. et al. (2014). ${ }^{17}$ GIC adheres chemically to tooth structure because they contain polyalkenoic acid. It forms a weak bond to tooth structure. In the current study the mode of failure for conventional and packable GIC specimens was cohesive within the material, which suggests that the values obtained may not be the strength of the bonded interface but the strength of the material. Attempts to increase the strength of the material may lead to increased bond strength values. SBS of RMGIC to primary tooth was $6.06 \pm 1.04 \mathrm{MPa}$ and to permanent tooth was $7.00 \pm 0.89 \mathrm{MPa}$. There was significant difference between the values of RMGIC for permanent and primary, the bond in permanent being higher which was in accordance to studies performed by Suryakumari et al. ${ }^{8}$, Holtan et al. (1990)18, Triana et al. (1994) ${ }^{19}$ and Bell and Barkmeier (1994) ${ }^{20}$ but in contrary to that performed by Raju S., Parbhakar A.R. and Raj S. in the year 2003.21 Significantly greater bond strength of RMGIC than that of conventional GIC was observed which can be due to their expected dual mechanism of bonding to tooth structure i.e. both chemical and micromechanical.22,23 The presence of light-activated resin component hydroxyethyl methacrylate (HEMA) with its superior wetting ability helps increase the bonding, also the slowness of acid-base reaction makes polyacid available for longer periods thus resulting in higher bond strength. The mode of failure recorded was predominantly mixed (cohesive within the material), which indicates that the values obtained were not clearly the strength of the bonded interface but due to inherent weakness of the material.

Mean SBS of compomer to primary tooth was found to be $10.27 \pm 1.38 \mathrm{MPa}$ and to permanent tooth was $12.54 \pm 1.36$ $\mathrm{MPa}$. These results are in agreement with previous study by elKalla IH, García-Godoy F.24 There was significant difference between the values of compomer for permanent and primary. The value in both the groups were significantly higher than the values for conventional or resin modified GIC. The higher bond strength can be explained due to application of PSA prime / adhesive to dentin prior to placement of compomer without any separate acid etching of enamel or dentin. The reported thicker hybrid layers and the consequently hypothesized inferior penetration are still being advocated to cause a less effective dentin bonding in deciduous teeth. ${ }^{25-28}$ The mode of failure in compomer specimens was adhesive failure with open and few empty dentinal tubules which suggests that the restorative and primer did not penetrate well in the tubules but the value obtained was of adhesive bond formed at the interface as mode of failure was predominantly adhesive.

The mean SBS of Giomer to primary tooth was $14.25 \pm 1.13$ $\mathrm{MPa}$ and for permanent was $15.26 \pm 1.54 \mathrm{MPa}$. The value in permanent was in agreement to that obtained by Manuja $\mathrm{N}$., Pundit I.K., Srivastava N., Gugnani N. and Nagpal R.29 There was significant difference between the values of Giomer for permanent and primary with values for permanent being higher. The mean shear bond strength of Giomer was higher than the values of both GIC and compomer. This could be due to acid etching and micromechanical bonding being involved. The mode of failure in Giomer specimens was adhesive failure which suggests that the value obtained was of adhesive bond formed at the interface.

SBS of composite to primary tooth in this study was 16.21 $\pm 1.12 \mathrm{MPa}$ and to permanent was $17.82 \pm 1.50 \mathrm{MPa}$. There was significant difference between the values of Composite for permanent and primary the value in permanent being 
significantly higher. This observation was in accordance with study done by Raju S., Parbhakar A.R. and Raj S. ${ }^{23}$ Hirayama et al revealed that peritubular dentin of the primary teeth was 2 - 5 times thicker than that of the permanent teeth so relatively less intertubular dentin is present. Since intertubular dentin is the major area where bonding occurs, primary teeth dentin provides lower bond strength with composite when compared to permanent teeth. ${ }^{30}$ The mode of failure in Composite specimens was adhesive failure which suggests that the value obtained is of adhesive bond formed at the interface.

\section{CONCLUSIONS}

Results of the present study showed that Giomer had the highest shear bond strength value, followed by Compomer, RMGIC and Packable GIC in decreasing order in both primary and permanent teeth groups. For all the restorative materials tested the bond strength of the restorative material to permanent teeth was higher than to primary teeth except for conventional and packable GIC where there was no significant difference between the values of primary and permanent. Though the shear bond strength value of packable GIC was higher to that of conventional GIC (negative control) but statistically there was no significant difference.

Hence within limitation of the present study, Giomer, Compomer and resin modified GIC proved to be the material with high adhesiveness to both primary and permanent tooth. Therefore, it can be recommended as a suitable restorative material for both primary and permanent teeth.

\section{Limitations}

The present study has an obvious limitation of being an in vitro study and does not exactly replicate the environmental condition of oral cavity. Also, results obtained from samples / materials which fail cohesively are not measures of actual bond strength but rather reflect weakness of the material. So, testing methods should be designed such that only adhesive fracture occurs.

The retention of a restorative material depends on various factors like size and shape of cavity, viscosity, and surface tension, of the restorative material. Thus, a more detailed study on factors related to adhesiveness is needed to yield more accurate results.

\section{Clinical Significance}

Shear bond strength of adhesive restorative materials helps clinician to make easy selection of material based on scientific background.

Data sharing statement provided by the authors is available with the full text of this article at jemds.com.

Financial or other competing interests: None.

Disclosure forms provided by the authors are available with the full text of this article at jemds.com.

I extend my gratitude to (Late) Dr. Bhaswar Bhattacharya for his valuable support and guidance. I am thankful to Dr Abhijit Chanda Prof. In-charge, School of Bioscience \& Engineering, Jadavpur
University, Kolkata, for his guidance in the technical aspect of the study.

\section{REFERENCES}

[1] Powers JM, Sakaguchi RL. Craig's Restorative dental materials. 12th edn. Elsevier 2006: p. 2.

[2] Espelid I, Cairns J, Askildsen JE, et al. Preferences over dental restorative materials among young patients and dental professionals. Eur J Oral Sci 2006;114(1):15-21.

[3] Wakefield CW, Kofford KR. Advances in restorative materials. Dental Clin North Am 2001;45(1):7-29.

[4] Wilson AD, McLean JW. Glass - ionomer cement. Chicago: Quintessence Publishing Co. Inc., 1988.

[5] Albers FH. Tooth coloured restoratives - principles and techniques. 9th edn. Hamilton, London: BC Decker Inc,, 2002: p. 58-9.

[6] Sirisha K, Rambabu T, Ravishankar Y, et al. Validity of bond strength tests: a critical review: Part. I. J Conserv Dent 2014;17(4):305-11.

[7] Mahler DB, Terkla LC. Analysis of stress in dental structures. DCNA: symposium on dental materials. Philadelphia: WB Saunders 1958.

[8] Nujella SBP, Choudhary MT, Reddy SP, et al. Comparison of shear bond strength of aesthetic restorative materials. Contemp Clin Dent 2012;3(1):22-6.

[9] Al - Salehi SK, Burke FJ. Methods used in dentin bonding tests: an analysis of 50 investigations on bond strength. Quintessence Int 1997;28(11):717-23.

[10] Pecora N, Yaman P, Dennison J, et al. Comparison of Shear bond strength relative to two testing devices. J Prosthet Dent 2002;88(5):511-5.

[11] Miyazaki M, Onose H, Moore BK. Effect of operator variability on dentin bond strength relative to two - step bonding systems. Am J Dent 2000;13(2):101-4.

[12] Dental materials - testing of adhesion to tooth structure Reference number ISO / TS 11405:2003(E).

[13] Strawn SE, White JM, Marshall GM, et al. Spectroscopic changes in human dentine exposed to various storage solutions short term. J Dent 1996;24(6):417-23.

[14] Rueggeberg FA. Substrate for adhesion testing to tooth structure. Review of the literature. Dent Mater 1991;7(1):2-10.

[15] Causton BE. In vitro assessment of dentin bonding agents. Today's Dentist, 1987. Proceedings of the International Symposium on Adhesion, its theory and practice in restorative dentistry. Current medical literature, London, 1827.

[16] Somani R, Jaidka S, Singh DJ, et al. Comparative evaluation of shear bond strength of various gics to dentin of primary teeth: an invitro study. Int J Clin Pediatr Dent 2016;9(3):192-6.

[17] Raju VG, Venmbaka NR, Mungara J, et al. Comparative evaluation of shear bond strength and microleakage of tricalcium silicate - based restorative material and radiopaque posterior glass ionomer restorative cement in primary and permanent teeth. J Indian Soc Pedod Prev Dent 2014;32(4):304-10.

[18] Holtan JR, Nystrom GP, Olin PS, et al. Bond strength of a light - cured and two auto - cured glass ionomer liners. J Dent 1990;18(5):271-5. 
[19] Triana R, Prado C, Garro J, et al. Dentin bond strength of fluoride - releasing materials. Am J Dent 1994;7(5):252-4.

[20] Bell RB, Barkmeier WW. Glass ionomer restoratives and liners: Shear bond strength to dentin. J Esthet Dent 1994;6(3):129-34.

[21] Prabhakar AR, Raj S, Raju OS. Comparison of shear bond strength of composite, compomer and resinmodified glass ionomer in primary and permanent teeth: an in vitro study. J Indian Soc Pedo Prev Dent 2003;21(3):86-94.

[22] Compton AM, Meyers Jr CE, Hondrum SO, et al. Comparison of the shear bond strength of a light cured glass ionomer and a chemically cured glass ionomer for use as an orthodontic bonding agent. Am J Ortho Dentofac Orthop 1992;101(2):138-44.

[23] Sonia G, van Meerbeek B, Lambrechts P, et al. Marginal adaptation and retention of glass ionomer, resin modified glass ionomer and a polyacid modified resin composite in cervical Class V lesions. Dent Mater 1998;14(4):294-306.

[24] El-Kalla IH, García-Godoy F. Bond strength and interfacial micromorphology of compomers in primary and permanent teeth. Int J Paediatr Dent 1998;8(2):103-14.
[25] Fritz U, Garcia-Godoy F, Finger WJ. Enamel and dentin bond strength and bonding mechanism to dentin of Gluma CPS to primary teeth. ASDC J Dent Child 1997;64(1):32-8.

[26] Malferrari S, Finger WJ, Garcia-Godoy F. Resin bonding efficacy of Gluma 2000 to dentine of primary teeth: an in vitro study. Int J Paediatr Dent 1995;5(2):73-9.

[27] Nor JE, Feigal RJ, Dennison JB, et al. Dentin bonding: SEM comparison of the resin-dentin interface in primary and permanent teeth. J Dent Res 1996;75(6):1396-403.

[28] Nor JE, Feigal RJ, Dennison JB, et al. Dentin bonding: SEM comparison of the dentin surface in primary and permanent teeth. Pediatr Dent 1997;19(4):246-52.

[29] Manuja N, Pandit IK, Srivastava N, et al. Comparative evaluation of Shear bond strength of various esthetic restorative materials to dentin: an in vitro study. J Indian Soc Pedod Prev Dent 2011;29(1):7-13.

[30] Hirayama A. Experimental analytical electron microscopic studies on the quantitative analysis of elemental concentrations biological thin specimens and its application to dental science. Shikwa Gakuho 1990;90(8):1019-36. 